\title{
Study on the Codimerization of Vinylaromatic Compounds with Ethylene in the Presence of Modified Nickel- Containing Catalysts
}

\author{
G. A. Mamedaliev and A. G. Azizov \\ Yu. G. Mamedaliev Institute of Petrochemical Processes, Academy \\ of Sciences, Azerbaijan SSR, 370025, Baku-25, \\ Telnov Str. 30, USSR
}

(Received March 1, 1984)

\begin{abstract}
The codimerization of vinylaromatic compounds with ethylene in the presence of nickel-containing catalysts modified with electron-acceptors was studied. $\mathrm{NiX}_{2}-\mathrm{P}\left(\mathrm{OC}_{6} \mathrm{H}_{5}\right)_{3}-$ $\mathrm{Al}\left(\mathrm{C}_{2} \mathrm{H}_{5}\right)_{3}-\mathrm{BF}_{3}\left(\mathrm{C}_{2} \mathrm{H}_{5}\right)_{2} \mathrm{O}$ systems have found to be highly effective catalysts for the codimerizations of vinylaromatic compounds with ethylene. A new method for selective synthesis of phenylbutenes has been developed. The reactivities of vinylaromatic compounds were studied in the codimerization reaction with ethylene. The monomer reactivities in the codimerization were found to be in the following order: $p$-chlorostyrene $>p$-methylstyrene $>\alpha$-methylstyrene $\gg \alpha$ phenylstyrene. The effect of different factors (nature and composition of catalyst component, method for preparing catalyst, monomer concentrations, reaction temperature) on the codimerization rate and selectivity was studied. The effect of solvent on the rate of styrene codimerization with ethylene was studied. The solvent with strong codimerization ability decreased catalytic activity. Detailed kinetic studies on the selective codimerization of styrene or $\alpha$-methylstyrene with ethylene were carried out. The results obtained were considered as proof for the "process of hydride mechanism" proceeding via the formation of nickel intermediate $\pi$-benzyl complexes. On the basis of proposed reaction mechanism, a kinetic equation has been derived; the rate constant and activation energy of ethylene insertion into $\mathrm{Ni}-\mathrm{C}$ bond in the intermediate $\pi$-benzyl complex were determined.
\end{abstract}

KEY WORDS $\alpha$-Methylstyrene / Codimerization / Ethylene / Styrene / 3Phenylbutene-1 / 2-Phenylbutene-2 / Vinylaromatic Compounds /

The interest in monomers of arylbutene series is due to the increased heat stability $\left(360^{\circ} \mathrm{C}\right)$ of their polymers as well as the possibility of converting these arylbutenes into 2arylbutadiene-1,3, indenes, high aromatic alcohols, acids, fragrant agents, insecticides, etc. Among the methods of arylbutene synthesis, the one most convenient and promising from the standpoint of commercial production is the codimerization of vinyl- and isopropenyl aromatic compounds with ethylene. The wellknown catalysts for the codimerization of vinylaromatic compounds with ethylene have a number of drawbacks such as low activity, poor selectivity, complexity of preparation, poor stability to trace water and oxygen.

In this connection, the development of new highly active catalytic methods for the selective codimerization of vinylaromatic compounds with ethylene is of significant practical interest. In addition, the investigation of new catalytic systems and a systematic study of selective codimerization open broad possibilities for elucidating the nature of active centers and the kinetics and mechanisms of dimerization or codimerization reactions of unsaturated hydrocarbons.

Until now in the literature, there are only a few works ${ }^{1-6}$ on the codimerization of vinylaromatic compounds (VAC) with ethylene. 
Analysis of this information indicates that high activity can be exhibited by nickel-containing catalytic systems. In this paper, we describe the results of a study on the codimerization reaction of VAC with ethylene in the presence of $\mathrm{Ni}$-containing Ziegler-Natta type catalysts.

\section{EXPERIMENTAL}

\section{Catalyst}

The catalyst was prepared by mixing the components in halohydrocarbon solvents in the presence of butadiene at below $0^{\circ} \mathrm{C}$ in the following sequence: nickel compounds, donor ligands, triethylaluminium, and activator.

\section{Chemicals}

Inorganic nickel(II) salts, $\mathrm{Ni}(\mathrm{acac})_{2}$, and $\mathrm{Ni}$ (palmitate $)_{2}$ were commercial reagents and used without further purification. 2,2'-Bipyridine or tri(aryl or alkoxy)phosphine compounds used as donor ligands were of a commercial source and used after recrystallization. $\mathrm{BF}_{3} \cdot \mathrm{Et}_{2} \mathrm{O}, \mathrm{CF}_{3} \mathrm{COOH}, \mathrm{BBr}_{3}$ or $\mathrm{TiCl}_{4} \cdot \mathrm{Et}_{2} \mathrm{O}$ used as activators were commercial reagents. Styrene, ethylene, and reaction solvents such as substituted aromatic solvents or halohydrocarbons were purified by distillation before use. Other chemicals were of reagent grade and used as received.

\section{Procedure}

The codimerization reaction was carried out in steel autoclaves equipped with magnetic stirrers, manometers and valves for fine adjustment of ethylene pressure under the conditions freed from trace moisture and oxygen gas. Ethylene gas the pressure of which was kept constant during the experiment was fed into the mixture of given amounts of the catalyst, styrene and solvent in the reaction vessel. The aliquots of the reaction mixtures were intermittently taken from the reaction vessel and analyzed by gas-liquid chromatography and spectroscopy to determine the yield of products that would indicate the reaction time for recovering the desired product. The solubility of ethylene gas changed when the initial feed of styrene or the reaction temperature was changed and so the ethylene gas pressure applied to each individual vessel was slightly different, so that the desired product could be obtained in the greatest yield. All kinetic alterations were made in a time range at which the content of desired product was more than $95 \mathrm{~mol} \%$ of all the products.

\section{Measurements}

Gas-liquid chromatography, NMR, IR, and mass spectroscopy were carried out by CHROM-5, Varian-25, IR-UR-20, respectively.

\section{RESULTS AND DISCUSSION}

Characteristic Features of Codimerization Vinylaromatic Compounds with Ethylene in the Presence of Modified Nickel-Containing Catalysts

The catalytic systems of $\left[\mathrm{NiX}_{2}\right.$-donor$\mathrm{Al}\left(\mathrm{C}_{2} \mathrm{H}_{5}\right)_{3}$-activator] types have been studied (Tables I and II). The characteristic feature of these systems is the high selectivity of their catalytic action. In contrast to codimerization of other pairs of lower olefins, that of styrene or its derivatives with ethylene proceeds with the formation of the sole product (3phenylbutene- 1 in case of styrene) to high

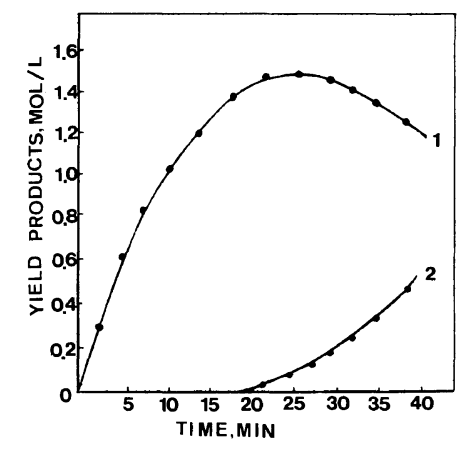

Figure 1. Products yield of styrene codimerization with ethylene. $[\mathrm{Ni}]_{0}=1 \times 10^{-2} \mathrm{~mol} \mathrm{l}^{-1} ;[\mathrm{St}]_{0}=1.7 \mathrm{mmol}$ $1^{-1} ; P_{\mathbf{E}}=10 \mathrm{~atm}$; curve 1, 3-phenylbutene-1; curve 2, 2-phenylbutene-2. 
Table I. Styrene codimerization with ethylene in the $\mathrm{NiX}$-donor- $\mathrm{Al}\left(\mathrm{C}_{2} \mathrm{H}_{5}\right)_{3}-$ activator (Ni-P-Al-B) catalytic system ${ }^{\mathrm{a}}$

\begin{tabular}{|c|c|c|c|c|c|c|c|c|c|}
\hline \multirow{3}{*}{ No } & \multicolumn{3}{|c|}{ Catalyst components } & \multirow{3}{*}{$\begin{array}{c}\begin{array}{c}\text { Ratio } \\
\text { of } \\
\text { Components }\end{array} \\
\mathrm{Ni}: \mathrm{P}: \mathrm{Al}: \mathrm{B}\end{array}$} & \multirow{3}{*}{$\frac{\text { Time }}{\min }$} & \multirow{2}{*}{$\begin{array}{c}\text { Styrene } \\
\text { consumption }\end{array}$} & \multicolumn{3}{|c|}{ Products yield } \\
\hline & \multirow{2}{*}{$\begin{array}{c}\text { Nickel } \\
\text { compound } \\
\mathrm{Ni}\end{array}$} & \multirow{2}{*}{$\begin{array}{c}\text { Donor } \\
\text { component } \\
\text { P }\end{array}$} & \multirow{2}{*}{$\begin{array}{c}\text { Activator } \\
\text { B }\end{array}$} & & & & & $\mathrm{mol} \%$ & \\
\hline & & & & & & $\%$ & 3-PhB-1 & 2-PhB-2 & $\begin{array}{c}\text { Oligo } \\
\text { (styrene) }\end{array}$ \\
\hline 1 & $\mathrm{Ni}\left(\mathrm{C}_{5} \mathrm{H}_{7} \mathrm{O}_{2}\right)_{2}$ & $\mathrm{P}\left(\mathrm{OC}_{6} \mathrm{H}_{5}\right)_{3}$ & $\mathrm{BF}_{3} \cdot\left(\mathrm{C}_{2} \mathrm{H}_{5}\right)_{2} \mathrm{O}$ & $1: 1: 3: 5$ & 22 & 90.0 & 97.0 & 3.0 & - \\
\hline 2 & $\mathrm{Ni}$ (palmit) $)_{2}$ & $\mathrm{P}\left(\mathrm{OC}_{6} \mathrm{H}_{5}\right)_{3}$ & $\mathrm{BF}_{3} \cdot\left(\mathrm{C}_{2} \mathrm{H}_{5}\right)_{2} \mathrm{O}$ & $1: 1: 3: 5$ & 25 & 71.0 & 100.0 & - & - \\
\hline 3 & $\mathrm{NiCl}_{2}$ & $\mathrm{P}\left(\mathrm{OC}_{6} \mathrm{H}_{5}\right)_{3}$ & $\mathrm{BF}_{3} \cdot\left(\mathrm{C}_{2} \mathrm{H}_{5}\right)_{2} \mathrm{O}$ & $1: 1: 3: 5$ & 40 & 51.0 & 100.0 & - & - \\
\hline 4 & $\mathrm{Ni}\left(\mathrm{C}_{5} \mathrm{H}_{7} \mathrm{O}_{2}\right)_{2}$ & $\mathrm{P}\left(\mathrm{CO}_{6} \mathrm{H}_{5}\right)_{3}$ & $\mathrm{TiCl}_{4} \cdot\left(\mathrm{C}_{2} \mathrm{H}_{5}\right)_{2} \mathrm{O}$ & $1: 1: 3: 2$ & 104 & 41.0 & 100.0 & - & - \\
\hline 5 & $\mathrm{Ni}\left(\mathrm{C}_{5} \mathrm{H}_{7} \mathrm{O}_{2}\right)_{2}$ & $\mathrm{P}\left(\mathrm{OC}_{6} \mathrm{H}_{5}\right)_{3}$ & $\mathrm{CH}_{3} \mathrm{COOH}$ & $1: 1: 3: 5$ & 300 & 22.0 & 100.0 & - & - \\
\hline 6 & $\mathrm{Ni}\left(\mathrm{C}_{5} \mathrm{H}_{7} \mathrm{O}_{2}\right)_{2}$ & $\mathrm{P}\left(\mathrm{OC}_{6} \mathrm{H}_{5}\right)_{3}$ & $\mathrm{BBr}_{3}$ & $1: 1: 3: 2$ & 22 & 100.0 & 66.5 & 23.4 & 10.1 \\
\hline 7 & $\mathrm{NI}\left(\mathrm{C}_{5} \mathrm{H}_{7} \mathrm{O}_{2}\right)_{2}$ & Dipyridine & $\mathrm{BF}_{3} \cdot\left(\mathrm{C}_{2} \mathrm{H}_{5}\right)_{2} \mathrm{O}$ & $1: 1: 3: 5$ & 74 & 4.2 & 100.0 & - & - \\
\hline 8 & $\mathrm{NiCl}_{2}$ & $\mathrm{P}\left(\mathrm{C}_{6} \mathrm{H}_{5}\right)_{3}$ & $\mathrm{BBr}_{3}$ & $1: 1: 5: 3$ & 56 & 100.0 & 58.7 & 1.3 & 40.0 \\
\hline
\end{tabular}

${ }^{\mathrm{a}}[\mathrm{St}]_{0}=1.70 \mathrm{~mol} \mathrm{l}^{-1} ;[\mathrm{Ni}]_{0}=0.01 \mathrm{~mol} \mathrm{l}^{-1}$, temperature $=25^{\circ} \mathrm{C}, P_{\mathrm{E}}($ partial pressure of ethylene $)=10 \mathrm{~atm}$.

conversion. The conversion curve for the styrene codimerization with ethylene has an extreme character (Figure 1). In the initial stage of codimerization, 3-phenylbutene-1 (3-PhB-1) is the only product, and its formation rate is equal to the rate of styrene consumption up to $80 \%$ conversion. A further increase in reaction time leads to a decrease in 3-PhB-1 yield due to its isomerization to the thermodynamically more profitable isomer 2-phenylbutene-2(2PhB-2). A similar dependence was observed in the codimerization of $p$-chlorostyrene and $p$ methylstyrene with ethylene. In the case of $\alpha$-methylstyrene, such isomerization was not observed and the yield of 3-methyl-3phenylbutene-1 (3-M-3-PhB-1) completely corresponded to the $\alpha$-methylstyrene consumption. Introduction of substituent groups at the vinyl group or phenyl ring of styrene changed the reactivity in the codimerization with ethylene as follows (Run No. 8-12 in Table II):

$$
\begin{gathered}
p \text {-Chlorostyrene }>\text { Styrene }>p \text {-Methylstyrene } \\
>\alpha \text {-Methylstyrene } \gg \alpha \text {-Phenylstyrene }
\end{gathered}
$$

The influence of catalyst preparation conditions, the nature and ratios of catalyst com- ponents and the properties of solvent and ratios of catalyst components and the properties of solvent and reaction period on the reaction rate and selectivity have been studied for styrene.

When nickel salt or its chelate complexes were used as nickel compounds, the activity of the system decreased in the order (Run No. 1-3 in Table I):

$\mathrm{NiCl}_{2}$

$\mathrm{Ni}(\text { acetylacetonate })_{2}>\mathrm{Ni}(\text { palmitate })_{2}>$

In this case, the reaction selectivity does not change (Table I).

The activity of the system has been found to depend strongly on the nature and concentration of donor component: $\mathrm{P}\left(\mathrm{OC}_{6} \mathrm{H}_{5}\right)_{3}$, $\mathrm{P}\left(\mathrm{C}_{6} \mathrm{H}_{5}\right)_{3}$, dipyridine. Increase in the phosphorous-containing ligand concentration or replacing it by dipyridine decreases the catalytic activity without changing the reaction selectivity. Without a donor, the system proves to be less active and nickel metal precipitation is observed during the catalyst preparation (Tables I and II).

$\mathrm{BF}_{3} \cdot\left(\mathrm{C}_{2} \mathrm{H}_{5}\right)_{2} \mathrm{O}, \mathrm{CF}_{3} \mathrm{COOH}, \mathrm{BBr}_{3}$, and $\mathrm{TiCl}_{4} \cdot\left(\mathrm{C}_{2} \mathrm{H}_{5}\right)_{2} \mathrm{O}$ were used as activators, Systems with $\mathrm{BF}_{3} \cdot\left(\mathrm{C}_{2} \mathrm{H}_{5}\right)_{2} \mathrm{O}$ showed the 


\section{G. A. Mamedaliev and A. G. Azizov}

Table II. Vinyl aromatic compounds (VAC) and codimerization with ethylene in the $\mathrm{Ni}\left(\mathrm{C}_{5} \mathrm{H}_{7} \mathrm{O}_{2}\right)_{2}-\mathrm{P}\left(\mathrm{OC}_{6} \mathrm{H}_{5}\right)_{3}-$ $\mathrm{Al}\left(\mathrm{C}_{2} \mathrm{H}_{5}\right)_{3}-\mathrm{BF}_{3} \cdot\left(\mathrm{C}_{2} \mathrm{H}_{5}\right)_{2} \mathrm{O}(\mathrm{Ni}-\mathrm{P}-\mathrm{Al}-\mathrm{B})$ catalytic system ${ }^{\mathrm{a}}$

\begin{tabular}{|c|c|c|c|c|c|c|c|}
\hline \multirow[t]{2}{*}{ No. } & \multirow{2}{*}{$\begin{array}{c}\text { Ratio of } \\
\text { components } \\
\text { Ni-P-Al-B }\end{array}$} & \multirow[t]{2}{*}{ VAC } & \multirow{2}{*}{$\frac{P_{\mathrm{E}}}{\mathrm{atm}}$} & \multirow{2}{*}{$\frac{\text { Time }}{\min }$} & \multirow{2}{*}{$\begin{array}{c}\text { VAC } \\
\text { consumption } \\
\%\end{array}$} & \multirow{2}{*}{$\begin{array}{c}\begin{array}{c}\text { Product } \\
\text { yield }\end{array} \\
\frac{0}{\%}\end{array}$} & \multirow[t]{2}{*}{ Products } \\
\hline & & & & & & & \\
\hline 1 & $1: 1: 3: 5$ & Styrene & 10 & 22 & 20.0 & 97 & 3-Phenyl butene-1 \\
\hline & & & & & & 3 & 2-Phenyl butene-2 \\
\hline 2 & $1: 2: 3: 5$ & Styrene & 10 & 22 & 23.5 & 100 & 3-Phenyl butene-1 \\
\hline 3 & $1: 0: 3: 5$ & Styrene & 10 & 22 & 10.0 & 100 & 3-Phenyl butene-1 \\
\hline 4 & $1: 1: 3: 1.5$ & Styrene & 10 & 22 & 5.8 & 100 & 3-Phenyl butene-1 \\
\hline 5 & $1: 1: 3: 3$ & Styrene & 10 & 22 & 38.2 & 100 & 3-Phenyl butene-1 \\
\hline \multirow[t]{3}{*}{6} & $1: 1: 3: 10$ & Styrene & 10 & 22 & 100.0 & 75 & 3-Phenyl butene-1 \\
\hline & & & & & & 13 & 2-Phenyl butene-2 \\
\hline & & & & & & 12 & Oligostyrene \\
\hline 7 & $1: 1: 10: 0$ & Styrene & 10 & 22 & 6.1 & 100 & 3-Phenyl butene-1 \\
\hline 8 & $1: 1: 3: 5$ & Styrene & 5 & 20 & 63.0 & 100 & 3-Phenyl butene-1 \\
\hline 9 & $1: 1: 3: 5$ & $\alpha$-Methyl styrene & 5 & 20 & 35.0 & 100 & 3-Methyl-3-phenyl butene-1 \\
\hline \multirow[t]{2}{*}{10} & $1: 1: 3: 5$ & p-Chlorostyrene & 5 & 20 & 74.0 & 95 & 3-( $p$-Chlorophenyl) butene-1 \\
\hline & & & & & & 5 & 2-(p-Chlorophenyl) butene-2 \\
\hline 11 & $1: 1: 3: 5$ & $p$-Methylstyrene & 5 & 20 & 50.0 & 100 & 3-Methyl phenyl butene-1 \\
\hline 12 & $1: 1: 3: 5$ & $\alpha$-Phenyl styrene & 5 & 20 & - & - & - \\
\hline
\end{tabular}

${ }^{\mathrm{a}}[\mathrm{Ni}]_{0}=0.01 \mathrm{~mol} \mathrm{l}^{-1},[\mathrm{VAC}]=1.70 \mathrm{~mol}^{-1}$, at $25^{\circ} \mathrm{C}, \mathrm{VAC}$, vinyl aromatic compound. $P_{\mathrm{E}}$, partial pressure of ethylene.

Table III. Selectivity of vinyl aromatic compounds (VAC) and codimerization with ethylene by $\mathrm{Ni}\left(\mathrm{C}_{5} \mathrm{H}_{7} \mathrm{O}_{2}\right)_{2}-\mathrm{P}\left(\mathrm{OC}_{6} \mathrm{H}_{5}\right)_{3}-\mathrm{Al}\left(\mathrm{C}_{2} \mathrm{H}_{5}\right)_{3}-\mathrm{BF}_{3} \cdot\left(\mathrm{C}_{2} \mathrm{H}_{5}\right)_{2} \mathrm{O}$ catalytic system ${ }^{\mathrm{a}}$

\begin{tabular}{|c|c|c|c|c|c|c|c|c|}
\hline \multirow{2}{*}{$\begin{array}{l}\text { Run } \\
\text { No. }\end{array}$} & \multirow{2}{*}{ VAC } & \multirow{2}{*}{$\frac{\mathrm{VAC}}{\mathrm{mol} \mathrm{l}^{-1}}$} & \multirow{2}{*}{$\frac{P_{\mathrm{E}}}{\mathrm{atm}}$} & \multirow{2}{*}{$\frac{\text { Time }}{\min }$} & \multirow{2}{*}{$\begin{array}{c}\text { VAC } \\
\text { codimerization }\end{array}$} & \multicolumn{3}{|c|}{$\frac{\text { Product yield }}{w t^{\circ} \%}$} \\
\hline & & & & & & $\begin{array}{l}\text { Phenyl } \\
\text { butenes }\end{array}$ & $\begin{array}{c}\text { VAC } \\
\text { oligomers }\end{array}$ & Butenes \\
\hline 1 & Styrene & 1.70 & 2 & 22 & 41.3 & 97.4 & 0.5 & 2.1 \\
\hline 2 & Styrene & 1.70 & 5 & 10 & 41.0 & 95.2 & Traces & 4.8 \\
\hline 3 & Styrene & 1.70 & 10 & 10 & 60.1 & 85.1 & Traces & 14.9 \\
\hline 4 & Styrene & 1.70 & 20 & 10 & 99.3 & 77.0 & - & 23.0 \\
\hline 5 & Styrene & 1.70 & 25 & 7 & 99.8 & 71.0 & - & 29.0 \\
\hline 6 & Styrene & 0.85 & 5 & 17 & 65.0 & 98.1 & - & 1.9 \\
\hline 7 & Styrene & 3.10 & 5 & 15 & 51.2 & 96.0 & 3.5 & 0.5 \\
\hline 8 & Styrene & 4.00 & 5 & 12 & 49.1 & 94.5 & 5.0 & 0.5 \\
\hline 9 & $\alpha$-Methylstyrene & 1.70 & 5 & 100 & 97.0 & 98.5 & - & 1.5 \\
\hline 10 & $\alpha$-Methylstyrene & 3.40 & 5 & 240 & 98.0 & 98.7 & - & 1.3 \\
\hline 11 & $\alpha$-Methylstyrene & 1.70 & 5 & 220 & - & - & - & - \\
\hline
\end{tabular}

${ }^{\mathrm{a}}[\mathrm{Ni}]_{0}=0.01 \mathrm{~mol} \mathrm{l}^{-1}$ at $25^{\circ} \mathrm{C}$, ratio of components $\mathrm{Ni}-\mathrm{P}-\mathrm{Al}-\mathrm{B}=1: 1: 3: 5 . P_{\mathrm{E}}$, partial pressure of ethylene.

greatest activity.

The catalytic activity depends mainly on the $\left[\mathrm{Al}\left(\mathrm{C}_{2} \mathrm{H}_{5}\right)_{3}\right.$ activator] ratio. In particular, on changing $\left[\mathrm{Al}\left(\mathrm{C}_{2} \mathrm{H}_{5}\right)_{3} / \mathrm{BF}_{3} \cdot\left(\mathrm{C}_{2} \mathrm{H}_{5}\right)_{2} \mathrm{O}\right]$ from $2 / 1$ to $2 / 3.2$ a drastic increase in activity was observed. A further increase in $\mathrm{BF}_{3} \cdot\left(\mathrm{C}_{2} \mathrm{H}_{5}\right)_{2} \mathrm{O}$ content leads to a decrease in $3-\mathrm{PhB}-1$ yield at the expense of styrene by the competitive 
cationic polymerization reaction (Table II).

The selectivity of the product depends on the monomer ratio. The greatest yield of 3PhB-1 was obtained at 2-10 atm of ethylene and $0.85-3.1 \mathrm{moll}^{-1}$ of styrene (Table III). The excess of this or another monomer leads to a decrease in 3-PhB-1 yield at the expense of either ethylene (by homodimerization) or styrene (by co-oligomerization). A different pattern was observed in the case of $\alpha$-methylstyrene: with an increase in $\alpha$-methylstyrene concentration, 3-M-3-PhB-1 yield reached a maximum value.

The solvent property has considerable effect on catalytic efficiency. When passing from aromatics to haloderivatives as solvents, the reaction rate sharply increases. However, in the presence of highly polar solvents such as ether or nitrobenzene, the system proves to be less effective. According to its activating effect, the solvents studied have the sequence:

$$
\begin{gathered}
\mathrm{CH}_{2} \mathrm{Cl}_{2}>\mathrm{C}_{6} \mathrm{H}_{5} \mathrm{~F}>\mathrm{C}_{6} \mathrm{H}_{5} \mathrm{Cl}>\mathrm{C}_{6} \mathrm{H}_{5} \mathrm{CH}_{3} \\
>\mathrm{C}_{6} \mathrm{H}_{5} \mathrm{NO}_{2}>\left(\mathrm{C}_{2} \mathrm{H}_{5}\right)_{2} \mathrm{O}
\end{gathered}
$$

\section{Kinetics and Mechanism of Vinylaromatic Compounds Codimerization Reaction with Ethylene}

The effect of styrene concentration on the codimerization rate has depended on the reaction temperature (Figure 2). At low temperature $\left(-30^{\circ} \mathrm{C}\right)$ the rate of $3-\mathrm{PhB}-1$ formation did not practically depend on the initial concentration of styrene (line 4). The rate dependence on styrene concentration, defined as the slope of the logarithmic line, increased with temperature to $25^{\circ} \mathrm{C}$ from zero to unity: 0.0 at $-30^{\circ} \mathrm{C}$ (line 4 ), 1.0 at $25^{\circ} \mathrm{C}$ (line 1). A similar dependence was observed in the case of $\alpha$-methylstyrene codimerization with ethylene. In this case, however, the independence of the reaction rate on $\alpha$-methylstyrene concentration was observed at higher temperature: 0.0 at $15^{\circ} \mathrm{C}$ (line 2), 0.6 at $25^{\circ} \mathrm{C}$ (line 3).

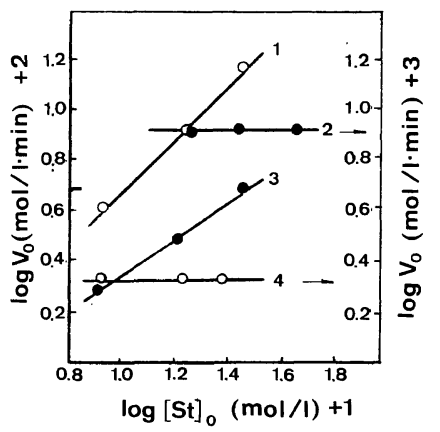

Figure 2. Codimerization initial rate $v s$. styrene (lines $1,4)$ and $\alpha$-methylstyrene (lines 2,3 ) concentration at different temperatures. $[\mathrm{Ni}]_{0}=1 \times 10^{-2} \mathrm{~mol} \mathrm{l}^{-1} ; P_{\mathrm{E}}=$ $5 \mathrm{~atm} ; T=25^{\circ} \mathrm{C}$ (line 1,3 ); $15^{\circ} \mathrm{C}$ (line 2 ); $-30^{\circ} \mathrm{C}$ (line 4).

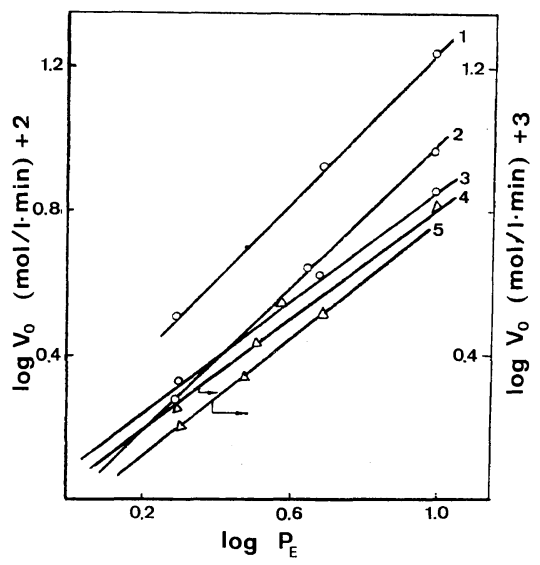

Figure 3. Initial rate of styrene (lines 1, 2, and 3) and $\alpha$ methylstyrene (lines 4,5 ) codimerization vs. ethylene pressure at different temperature. $[\mathrm{Ni}]_{0}=1 \times 10^{-2} \mathrm{~mol}$ $1^{-1} ;[\mathrm{St}]_{0}$ and $[\alpha-\mathrm{MeSt}]_{0}=1.7 \mathrm{~mol} \mathrm{1}^{-1} ; T=25^{\circ} \mathrm{C}$ (lines 1 , 5); $15^{\circ} \mathrm{C}$ (line 2 ); $5^{\circ} \mathrm{C}$ (line 4$) ;-30^{\circ} \mathrm{C}$ (line 3 ).

In both cases at low temperature, the rate of reaction did not practically depend on time, while the temperature rise led to a decrease in the rate of reaction with time. The straight line nature of semilogarithmic anamorphosis of kinetic curves shows the rate fall at $25^{\circ} \mathrm{C}$ to be due to only the decrease in the concentration of styrene with time by first order but not to the destruction of active centres. This was also confirmed by the fact that an increase in catalyst aging time from $25 \mathrm{~min}$ to $17 \mathrm{~h}$ had little effect on the system activity. 
The effect of ethylene pressure (at constant [St] of $[\alpha-\mathrm{MeSt}])$ on the codimerization rate (Figure 3) was examined, and the characteristic dependence of reaction rate with respect to the ethylene pressure was found. Under the conditions of zero order with respect to styrene (or $\alpha$-methylstyrene) the order with respect to ethylene was below unity. In contrast, when the codimerization rate was directly propotional to styrene concentration, the order of ethylene was also unity. It should be noted that in the range of ethylene pressure and styrene concentration shown in figure, only a trace amount of ethylene dimer was found at the initial stage of the reaction. Thus, the contribution of homodimerization of ethylene may be neglected.

The effect of catalyst concentration on codimerization showed a linear relationship between the initial rate and catalyst concentration. The above kinetic data indicate that the reaction rate obeys the following equation.

$$
V_{0}=K \cdot[\mathrm{Ni}]_{0} \cdot\left[\mathrm{M}_{1}\right]_{0}^{n} \cdot\left[\mathrm{M}_{2}\right]_{0}^{m}
$$

where $n$ and $m$ vary in the range $0 \leq n \leq 1$ and $0<m \leq 1$ depending on the experimental conditions, and $[\mathrm{Ni}]_{0},\left[\mathrm{M}_{1}\right]_{0}$, and $\left[\mathrm{M}_{2}\right]_{0}$ denote the initial concentration of catalyst, styrene and ethylene, respectively.

The temperature effect on the rate of styrene codimerization with ethylene was studied at $[\mathrm{Ni}]_{0}=1.10^{-2} \mathrm{moll}^{-1},\left[\mathrm{M}_{1}\right]_{0}=1.7 \mathrm{moll}^{-1}$ and at $35,25,15$, and $5^{\circ} \mathrm{C}$. Within the indicated temperature range, a small change in the reaction order of styrene was observed from "0.7" to "1.0." However the temperature dependence of the rate obeys the Arrhenius equation and the apparent activation energy $\left(E_{\mathrm{a}}\right)$ was estimated to be $11.5 \mathrm{kcal} \mathrm{mol}^{-1}$ A similar pattern was observed for $\alpha$ methylstyrene codimerization with ethylene $\left(E_{\mathrm{a}}=17 \mathrm{kcal} \mathrm{mol}^{-1}\right)$.

We previously found that the $\mathrm{Ni}$ (acetylacetonate) $\cdot \mathrm{P}\left(\mathrm{OC}_{6} \mathrm{H}_{5}\right)_{3}$ complex reacts with $\mathrm{Al}\left(\mathrm{C}_{2} \mathrm{H}_{5}\right)_{3}$ in the medium of halohydrocarbons (RX), leading to a completely homo- geneous system and forming organometal compounds such as $\mathrm{RNi} \cdot \mathrm{P}\left(\mathrm{OC}_{6} \mathrm{H}_{5}\right)$ as a result of the oxidative $\mathrm{RX}$-addition which reduces the nickel center as follows ${ }^{7-10}$ :

$$
\begin{aligned}
& \mathrm{Ni}\left(\mathrm{C}_{5} \mathrm{H}_{7} \mathrm{O}_{2}\right)_{2} \cdot \mathrm{P}\left(\mathrm{OC}_{6} \mathrm{H}_{5}\right)_{3} \\
& \quad+\mathrm{Al}\left(\mathrm{C}_{2} \mathrm{H}_{5}\right)_{3} \stackrel{\mathrm{RX}}{\longrightarrow} \mathrm{RNiX} \cdot \mathrm{P}\left(\mathrm{OC}_{6} \mathrm{H}_{5}\right)_{3}
\end{aligned}
$$

The presence of the latter has been confirmed by the number of hydlyzable halide atoms determined according to Folgard ${ }^{13}$ as well as by the formation of $\pi$-allyl complexes of nickel when interacted with butadine

$$
\mathrm{RNiX} \cdot \mathrm{P}\left(\mathrm{OC}_{6} \mathrm{H}_{5}\right)_{3}+\mathrm{C}_{4} \mathrm{H}_{6} \longrightarrow
$$

These species were identified by IR and UVspectroscopy. ${ }^{7}$

IR-spectra show that the $\mathrm{BF}_{3} \cdot\left(\mathrm{C}_{2} \mathrm{H}_{5}\right)_{2} \mathrm{O}$ addition to the system forms the complex of organo-metal compounds of nickel with fluoroderivatives of $\mathrm{Al}$ and $\mathrm{B}$ which are responsible for the catalytic properties of the system.

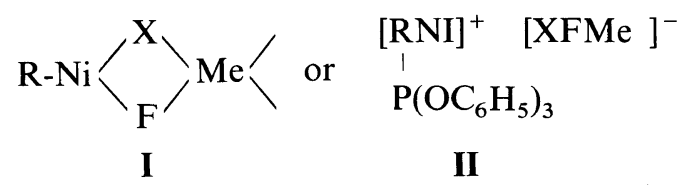

In the styrene codimerization with ethylene, six isomers can be theoretically expected: 3phenylbutene-1, 2-phenylbutene-2, 4-phenylbutene-1, 1-phenylbutene-1, 1-phenylbutene2 , and 2-phenylbutene-1. The selective formation of 3-PhB-1 in the presence of ZieglerNatta type co-catalysts suggests the "hydride" nature of intermediate catalytic center arising as a result of $\beta$-elimination from the intermediate organometal complexes of nickel. Earlier works by Japanese scientists ${ }^{11}$ have shown similar results in the codimerization of styrene with ethylene in the presence of two 
types of palladium systems such as $\left(\mathrm{PdCl}_{2}\right.$. $\left.\mathrm{C}_{6} \mathrm{H}_{5} \cdot \mathrm{CH}=\mathrm{CH}_{2}\right)_{2}$ and $\left(\pi-\mathrm{C}_{3} \mathrm{H}_{5} \mathrm{PdCl}\right)_{2}+$ $\mathrm{BF}_{3} \cdot \mathrm{P}\left(\mathrm{C}_{6} \mathrm{H}_{5}\right)_{3}$. The former system without $\mathrm{Pd}-\mathrm{C}$ bond has been shown to lead to 1 phenylbutene-1 formation while the system by the $\pi$-allyl complex gives rise to 3 -PhB-1. In addition, the 3-PhB-1 formation unequi- valently proves that hydride addition at the double bonds of vinyl aromatic monomer is effected strictly in accordance with the anti Markovnikov rule.

Based on the above results, the following reaction scheme is proposed:

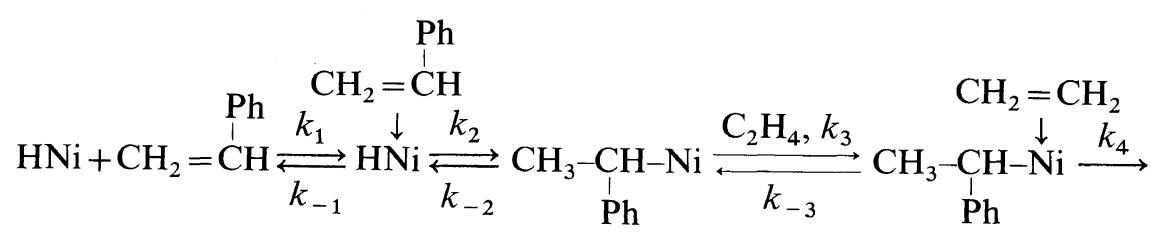

$$
\begin{aligned}
& \text { I II III IV }
\end{aligned}
$$

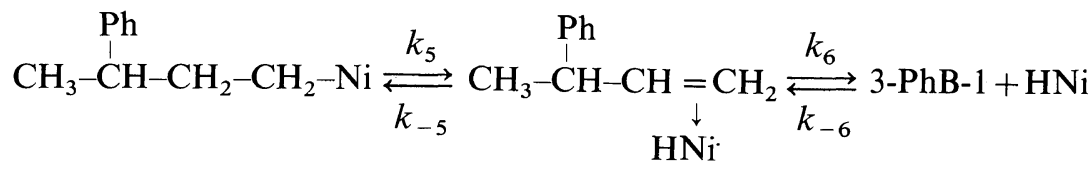

$$
\begin{aligned}
& \text { V VI }
\end{aligned}
$$

Since in the initial regions of the reaction, the other products besides 3-PhB-1 are not formed in a marked quantity, the reverse reactions can be neglected at the $\mathbf{V}$ and VI

$$
V_{0}=\frac{\mathrm{d} P}{\mathrm{~d} t}=\frac{k_{4} \cdot K^{\mathrm{I}} \cdot K^{\mathrm{II}} \cdot K^{\mathrm{III}} \cdot \beta[\mathrm{Ni}]_{0} \cdot\left[\mathrm{M}_{1}\right]_{0} \cdot\left[\mathrm{M}_{2}\right]_{0}}{1+\left\{K^{\mathrm{I}}+K^{\mathrm{I}} \cdot K^{\mathrm{II}}+K^{\mathrm{I}} \cdot K^{\mathrm{II}} \cdot K^{\mathrm{III}}\left[\mathrm{M}_{2}\right]_{0}\right\} \cdot\left[\mathrm{M}_{1}\right]_{0}}
$$

or

$$
\frac{[\mathrm{Ni}]_{0}}{V_{0}}=\frac{1}{k_{4} \cdot \beta \cdot K^{\mathrm{I}} \cdot K^{\mathrm{II}} \cdot K^{\mathrm{III}}\left[\mathrm{M}_{2}\right]_{0}} \cdot \frac{1}{\left[\mathrm{M}_{1}\right]_{0}}+\left\{\frac{K^{\mathrm{I}}+K^{\mathrm{I}} \cdot K^{\mathrm{II}}}{k_{4} \cdot \beta \cdot K^{\mathrm{I}} \cdot K^{\mathrm{II}} \cdot K^{\mathrm{III}}\left[\mathrm{M}_{2}\right]_{0}}+\frac{1}{k_{4}}\right\}
$$

Here $P$ is the codimer yield; $[\mathrm{Ni}]_{0},\left[\mathrm{M}_{1}\right]_{0}$, and $\left[\mathrm{M}_{2}\right]_{0}$ are initial concentrations of nickel compounds, styrene and ethylene, respectively; $\beta$ is the fraction of active centres from $[\mathrm{Ni}]_{0} ; K^{\mathrm{I}}$, $K^{\mathrm{II}}, K^{\mathrm{III}}$ are stability constants of II, III, and IV complexes; and $k_{4}$ is rate constant of the insertion reaction of ethylene into $\mathrm{Ni}-\mathrm{C}$ bond.

In Figure 4 are presented the experimental data in the coordinates of $[\mathrm{Ni}]_{0} / V_{0} \sim 1 / P_{\mathrm{E}}\left(P_{\mathrm{E}}\right.$, partial pressure of ethylene) and $[\mathrm{Ni}]_{0} / V_{0} \sim$
$1 /\left[\mathrm{M}_{1}\right]_{0}$, respectively. The linear relationship at the different reaction temperatures when the temperature increases, the section at $Y$ axis approaches zero (passing from zero order to the first order). Thus eq 1 and 2 derived from the hydride mechanism of codimerization agree with the dependence of the reaction rate on the monomer concentration as described above (see Figures 2 and 3). The reaction orders of reactive monomers can thus change from zero to the first order. In fact, if 

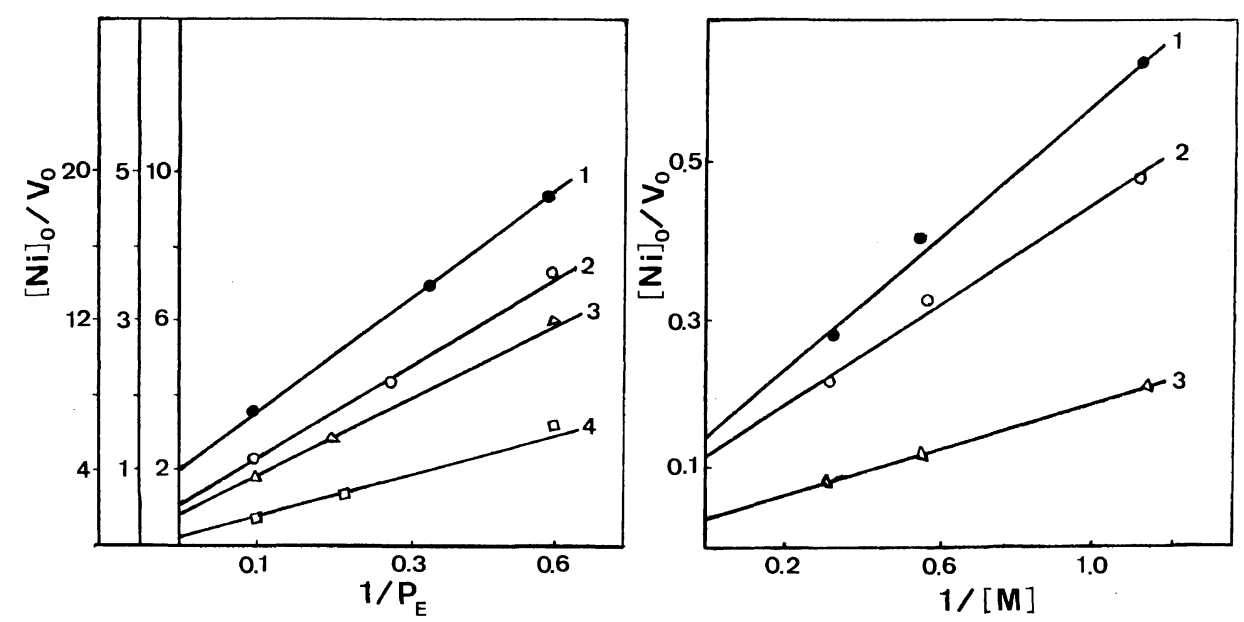

Figure 4. Relationship of the codimerization rate with ethylene in coordinates of eq 2.

a) $[\mathrm{Ni}]_{0}=1 \times 10^{-2} \mathrm{moll}^{-1} ;[\mathrm{St}]_{0}$ and $[\alpha-\mathrm{MeSt}]_{0}=1.7 \mathrm{~mol}^{-1} ;$ styrene $T=-30^{\circ} \mathrm{C}($ line 1$) ; 5^{\circ} \mathrm{C}($ line 2$), 25^{\circ} \mathrm{C}$ (line 4); $\alpha$-methylstyrene $25^{\circ} \mathrm{C}$ (line 3).

b) $[\mathrm{Ni}]_{0}=1 \times 10^{-2} \mathrm{~mol} \mathrm{l}^{-1} ; P_{\mathrm{E}}=5 \mathrm{~atm} ; T=5^{\circ} \mathrm{C}$ (line $\left.1, \mathrm{St}\right) ; 25^{\circ} \mathrm{C}$ (line $\left.2, \alpha-\mathrm{MeSt}\right) ; 25^{\circ} \mathrm{C}$ (line $3, \mathrm{St}$ ).

Table IV. Kinetic parameters of vinyl aromatic compounds (VAC) and codimerization with ethylene

\begin{tabular}{|c|c|c|c|c|c|}
\hline \multirow{2}{*}{ VAC } & \multirow{2}{*}{$\begin{array}{c}\text { Temp } \\
{ }^{\circ} \mathrm{C}\end{array}$} & \multirow{2}{*}{$\frac{\left(\mathrm{V}_{0}\right)_{\mathrm{VAC}}}{\left(\mathrm{V}_{0}\right)_{\mathrm{St}}}$} & \multirow{2}{*}{$K^{\mathrm{I}}+K^{\mathrm{I}} \cdot K^{\mathrm{II}}$} & \multirow{2}{*}{$K^{\mathrm{I}} \cdot K^{\mathrm{II}} \cdot K^{\mathrm{III}}$} & \multirow{2}{*}{$\frac{k_{4}}{\mathrm{~S}^{-1}}$} \\
\hline & & & & & \\
\hline \multirow[t]{4}{*}{ Styrene } & -30 & - & - & - & $1.01 \pm 0.03$ \\
\hline & 5 & - & 0.028 & 0.041 & $8.07 \pm 0.27$ \\
\hline & 15 & - & - & - & $21.38 \pm 1.25$ \\
\hline & 25 & - & 0.016 & 0.026 & $37.35 \pm 2.88$ \\
\hline \multirow[t]{3}{*}{$\alpha$-Methylstyrene } & 5 & 0.17 & - & - & $1.22 \pm 0.30$ \\
\hline & 15 & 0.26 & - & - & $3.46 \pm 0.75$ \\
\hline & 25 & 0.43 & 0.034 & 0.062 & $9.75 \pm 2.00$ \\
\hline$\alpha$-Phenylstyrene & 25 & 0 & - & - & - \\
\hline$p$-Methylstyrene & 25 & 0.78 & - & - & - \\
\hline$p$-Chlorostyrene & 25 & 1.68 & - & - & - \\
\hline
\end{tabular}

the value of the sum of the second term in eq 1 is greater than unity, the reaction orders with respect to styrene and ethylene become 0 or less than unity, respectively. In contrast, when the value is less than unity, both reaction orders become unity. The zero order for styrene (or $\alpha$-methylstyrene) and the fractional one for ethylene result from the greater stability of the II, III, and IV intermediate complexes at low temperature. Equation 2 allows us to estimate $k_{4}, K^{\mathrm{I}} \cdot K^{\mathrm{II}} \cdot K^{\mathrm{III}}$ and $K^{\mathrm{I}}+K^{\mathrm{I}} \cdot K^{\mathrm{II}}$ from the relationship, $[\mathrm{Ni}]_{0} / V_{0}$ vs. $1 / P_{\mathrm{E}}$ and
$1 /\left(M_{1}\right)_{0}$. In this case, it is not ethylene concentration but pressure that effects the estimated values of $k_{4}$ and combinations of intermediate complexes stability constants include the solubility coefficient of ethylene. The data in Table IV show that with decrease in temperature, the complex stability constant values increase, causing $K^{\mathrm{I}}+K^{\mathrm{I}} \cdot K^{\mathrm{II}}$ and $K^{\mathrm{I}} \cdot K^{\mathrm{II}} \cdot K^{\mathrm{III}}$ to become greater. In addition, they increase also by replacing styrene with $\alpha$-methylstyrene because of the greater stability of the $\alpha$-methylstyrene intermediate 
$\pi$-complexes.

Analysis of the equations shows the increase in the stability constants to lead increased reaction rates while the experimental results indicate the decrease in reaction rate as a result of using $\alpha$-methylstyrene instead of styrene with decreasing temperature. This is due primarily to the fact that $k_{4}$ constants obey the following temperature dependence expressions.

$$
k_{4}=1.4 \times 10^{7} \cdot \exp \left(\frac{10060 \pm 200}{R \cdot T}\right) \mathrm{s}^{-1}
$$

for styrene

$$
k_{4}=5.8 \times 10^{11} \cdot \exp \left(\frac{17100 \pm 600}{R \cdot T}\right) \mathrm{s}^{-1}
$$

$\alpha$-methylstyrene

Hence, the kinetic study confirm the assumption that ethylene insertion into the $\mathrm{Ni}-\mathrm{C}$ bond is the main factor determining VAC reactivity in codimerization with ethylene.

The increase in activation energies of both the over-all reaction and ethylene insertion stage by replacing styrene with $\alpha$-methylstyrene deserves attention. This cannot be explained by increase in the stability of the $\mathrm{Ni}-\mathrm{C}$ bond in complex IV in the case of $\alpha$ methylstyrene, since the presence of an additional substituent with a negative inductive effect at carbon atom should lead to a decrease in bond strength.

The increase in activation energy of the over-all reaction can be explained assuming that in the intermediate III and IV complexes, the nickel center is covalently bonded to the organic group through a $\pi$-benzyl bond.

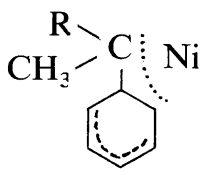

In the case of the nickel $\pi$-allyl complexes (having some of the characteristics of the metal-carbon bond in $\pi$-benzyl complexes) in- troduction of the substituents with positive inductive effects increases the stability of the metal-carbon bond against decomposition. It may thus be assumed that the intermediate IV complex of $\alpha$-methylstyrene should be more stable and hence is less reactive towards the ethylene introduction, as evident from the large activation energy of the over-all reaction. A higher activation energy should be expected for the codimerization of $\alpha$-phenylstyrene with ethylene since the strengh of the metalcarbon bond in this intermediate complex is much greater. This may be the main reason for the low reactivity of $\alpha$-phenylstyrene, and the system completely inhibits even homodimerization of ethylene as well as codimerization. It is quite difficult to explain why the preexponential values differ from those of the elementary monomolecular reactions, since they are greatly influenced by the amount of active portions of the nickel complexes.

The results of our kinetic studies show that the reaction proceeds through a "hydride mechanism" with the formation of nickel $\pi$ benzyl complexes. At high styrene conversions, the contributory reverse reaction proceeds more rapidly at stages $\mathrm{V}$ and VI, leading to the isomerization of 3-PhB-1 toward 2-PhB2.

\section{REFERENCES}

1. Y. Kawamoto, T. Imanaka, and S. Teranishi, Kogyo Kagaku, 72, 1612 (1969).

2. Y. Kawamoto, T. Imanaka, and S. Teranishi, Bull. Chem. Soc. Jpn., 43, 2512 (1970).

3. T. Alderson, E. L. Jenner, and R. V. Lindsey, Jr., J. Am. Chem. Soc., 87, 5638 (1965).

4. U.S.A. Patent, 3013066 (1961).

5. Holland Patent, 68,13476 (1967).

6. N. Kawata, K. Maruya, T. Mizoroki, and A. Ozaki, Bull. Chem. Soc. Jpn., 47, 2003 (1974).

7. G. Mamedaliev, K. Vurshikov, A. Azizov, and S. Áliev, Azerb. Chem. J., 6 (1976).

8. A. Azizov, G. Mamedaliev, and S. Aliev, Azerb. Chem. J., 2 (1977).

9. G. Mamedaliev, A. Azizov, S. Aliev, and V. Aliev, Azerb. Chem. J., 2 (1978).

10. D. Armstrong, Inorg. Chim. Acta, 17, 125 (1976).

11: N. Kawakami, K. Kawata, K. Maruya, T. Mizoroki, 
G. A. Mamedaliev and A. G. Azizov

and A. Ozaki, J. Catalysis, 39, 134 (1975).

12. P. W. Jolly and O. Wilke, "The Organic Chemistry of Nickel," Vol. 1, Academic Press, New York, London,
1974.

13. A. P. Kreshkov, "Osnovy Analiticheskoi Chmii," t. 2, Izdachelistbo Chimiya, Moskva, 1976. 